\title{
Exotopía e literatura de fronteira galegas: O caso do Grupo Bilbao
}

\author{
Xavier Frías Conde \\ UNED \\ xfrias@flog.uned.es \\ Luis Miguel LunA \\ UNED \\ lmluna@invi.uned.es \\ Recibido: marzo de 2014. Aceptado: abril de 2014.
}

Resumo: O presente estudo tenta actualizar o estudo da literatura galega extraterritorial, isto é, aquela escrita e publicada fóra das fronteiras xeográficas da Comunidade Autónoma Galega. A dita produción, fortemente marxinalizada decote, non adoita recibir a atención dos expertos, malia existir o feito de que os máximos expoñentes da literatura galega como tal pasaron unha parte do seu percurso histórico fóra do país, quer noutros lugares de España, quer no estranxeiro. Estes grupos supuxeron concentracións de creación e de ancoraxe á lingua e á cultura galegas, embora en condicións normalmente máis difíciles ou adversas que os grupos do interior do país.

Palabras clave: Grupo Bilbao, exotopía, literatura galega.

Resumen: El presente estudio intenta actualizar el estudio de la literatura gallega extraterritorial, es decir, aquella escrita y publicada fuera de las fronteras geográficas de la Comunidad Autónoma de Galicia. Dicha producción, profundamente marginada en ocasiones, no suele recabar la atención de los estudiosos, a pesar, incluso, de que si hacemos una recensión histórica, los máximos exponentes de la literatura gallega como tal pasaron una parte de su devenir vital fuera del país, bien en otros lugares de España, bien en el extranjero. Esos grupos son, en realidad, concentraciones de creación y de anclaje a la lengua y la cultura que les es propia y, en último término, órganos de normalización y difusión de la lengua y la cultura gallegas, si bien en condiciones normalmente más difíciles o adversas que los grupos del interior del país.

Palabras clave: Grupo Bilbao, exotopía, literatura gallega. 


\section{INTRODUCIÓN}

Mal existe unha identificación asumida por parte do canon literario galego da existencia de grupos literarios de expresión galega fóra do ámbito territorial de Galiza. Aprécianse marxinalizacións ou postergacións dos autores que viven e publican fóra de Galiza, embora o seu labor poida ser excepcional e a súa escrita non se afaste do que fan os seus compañeiros de xeración -se por acaso este concepto pode ser usado con propiedade aquí- están a desenvolver en Galiza. Por tanto, o labor destes grupos é crucial para entender e interpretar a creación galega, nomeadamente a contemporánea. Durante toda a posguerra, o exilio permite aos grandes escritores galegos seguiren a crear e desenvolver a súa lingua, de xeito que o exterior será, logo, o foco máis salientábel da normalización e creación en lingua galega.

Coa chegada da democracia a partir da segunda metade da década de 1970, hase concentrar na creación de grupos aglutinantes, arredor dos cales se forxarán diversas publicacións, por norma de carácter periódico, como revistas ou fancíns. É nese contexto que nace o Grupo Bilbao (GB), particularmente relevante pola altura dos seus integrantes, a cohesión entre diversos ámbitos (universitario, cultural e social), a extensión no tempo e mais a frecuencia nas súas actuacións e publicacións.

Non podemos deixar de sinalar un certo paradoxo que se dá entre a apreciación que o canon galego dedica á literatura feita no exterior durante o franquismo e a que lle dedica ao período posterior. Mentres que a primeira ocupa capítulos enteiros dos manuais de historia da literatura galega, a segunda mal aparece e é case ignorada arreo. As razóns disto son complexas. Probabelmente ten moito a ver coa identificación entre literatura e país que moitos especialistas establecen nos primeiros tempos da normalización galega no inicio da década de 1980, que envolve un estraño concepto de que o autor galego teña que vivir no país, xa que o concepto de autor exiliado non pode ser aplicado aos escritores que viven fóra de Galiza como emigrados. Neste estudo, porén, imos referirnos a eses autores galegos e non galegos que escriben en galego sen residiren en Galiza e que fican incluídos no concepto que nos ocupa: a exotopía, máis concretamente a exotopía galega.

O GB non é nin foi o único grupo de fronteira da literatura galega. Por unha banda, existiron precedentes no mesmo Madrid, mais tamén en Barcelona, sen esquecermos a literatura do exilio, nomeadamente en Buenos Aires. Por outra banda, cada grupo ten unhas características de seu e neste estudo imos fixarnos exclusivamente no Grupo Bilbao, do cal fan parte os autores deste estudo.

\section{EXOTOPÍA E LITERATURA GALEGA DE FRONTEIRA}

É preciso abordar o concepto de exotopía aplicado á literatura galega de fronteira como un fenómeno moi relevante que nos estudos actuais non aparece. Interesounos aplicar o concepto de Todorov $(1987,260)$ entendido como a superación do monologuismo das literaturas nacionais. A dita aplicación foi efectua- 
da con éxito no eido das culturas minoritarias, desde o campo da socioloxía, mais tamén no estudo das literaturas en contacto, fortemente retroalimentadas. A exotopía como «mirada desde fóra» foi explorada por Iris Zavala (1996), para se referir á(s) literatura(s) de fronteira:

Pero frontera significa muchas cosas: lo que divide y limita. El problema está en quién limita y por qué se limita: lo dicho en Bajtin: la frontera rehuye el centro, está en los márgenes, y desde los márgenes puede corroer el edificio de homogeneización creado por el universalismo centralista, que como fuerza centrífuga o como el ojo del huracán, intenta absorberlo todo, engullirlo para crear una falsa ilusión de igualdad homogénea.

Esta tentativa de homoxeneización envolve que, desde un punto de vista sociolóxico, o GB teña sido, como xa dixemos anteriormente, sistematicamente ignorado pola maioría dos axentes culturais galegos ou, no mellor dos casos, neglixenciado. A exotopía, entendida neste caso como a creación sobre ou en galego da sociedade e a literatura galegas desde lugares fóra das fronteiras de Galiza, permite a reflexión diferida, a análise detallada sen se someter ás correntes de opinión imperantes e, nomeadamente, a creación desde diversos puntos de vista diverxentes dos do canon literario en vigor en Galiza. No concernente ao GB, este fenómeno tórnase particularmente relevante, pois os seus membros organizan toda a caste de actos culturais partindo dunha situación de lingua allea a Madrid e coa escasa repercusión que teñen as súas accións dentro de Galiza.

A respecto da súa relación coa endotopía, é de destaque en noutros colectivos importantes da diáspora, como os chicanos emigrados nos Estados Unidos, o canon mexicano ofrece unha forte resistencia ao recoñecemento dos valores que fornece a súa creación literaria. Así o manifiesta Zavala (1996):

Debiéramos comenzar por abordar la noción de frontera desde la hibridez espacial y cultural que el fenómeno presenta, un espacio liminal en el que El mismo y el Otro están en constante fluctuación, en constante interpelación y en constante conflicto, ya que la función de este espacio es precisamente la de dividir el más allá de la frontera del más acá. Me interesa indagar qué pasa en ese espacio (más que en los espacios que divide). Como ejemplo, se podría recurrir a diversas localidades fronterizas en el mundo: resulta ostensible la de Estados Unidos y México(...)hoy por hoy la frontera es un concepto teórico y filosófico: Trías alude a su filosofía fronteriza, y Walter Mignolo ha creado la noción de bordergnosis, asimismo las chicanas, Gloria Anzaldúa, Norma Alarcón y hasta el mismo Juan Goytisolo, han aludido a las diferencias, en una breve extrapolación que va de Tijuana al Ejido.

A mesma cousa acontece co GB, cuxos integrantes acostuman destacar as fortes reticencias que atopan para a súa integración e o resgate da parte das editoras galegas. Este «esquecemento» vira aínda máis patente nos manuais de historia da literatura galega dedicados a este período. De entre as fontes consultadas, só unha estuda o realizado en Barcelona e Madrid. Trátase do libro pre- 
parado por Anxo Tarrío Varela para Xerais (Tarrío Varela, 1994). Outras fontes secundarias destacan apenas a figura de Vicente Araguas ou Fermín Bouza, cuxa importancia non puido ser ocultada polo canon.

A pregunta que fica no ar é: pasa a canonización por vivir en Galiza? Parece que si. Para iso, vexamos o caso de Rafa Yáñez para ilustrar o que vimos analizando. A súa obra poética foi avalada polos poetas Vicente Araguas, Manuel Pereira e Xavier Frías e mais a estudiosa Carmén Mejía. Vicente Araguas dicía sobre el:

Eu lera con interese a anterior entrega poética deste escritor chairego. Nela había un non sei que de elevación que me intriga, que me pon a matinar en peixes e paxaros, que me fai apostar duramente polo proceso poético no que Rafa Yáñez vai enviso. Rafa, en fin, escribe suaviño pero con moita forza detrás de canto di. Luvas de seda para unha man de ferro, termando dun leme cada vez máis seguro. E agora teño diante miña, coma ti, curioso lector, Lembranzas e olvidos dun estraño, a nova incursión poética de Rafa Yáñez. Un libro que comeza moi Manuel Antonio, moi amparándose en Walt Whitman, para ir adelgazando pretensións e contidos. E ollo, que isto no é cousa mala. Ben ao contrario; quere dicir que Rafa Yáñez ceiba un son de trompetería a meia noite -para maior escándalo- adicado ademais a Corto Maltese, e logo vai deixando no camiño instrumentos no tan sonoros. (Yáñez, 2001)

Como vemos, os seus textos están moi ben considerados por Araguas, quen non hesita en mostrar a súa debilidade pola actividade poética do escritor na altura aínda mozo. Este recoñecemento lévalle a gañar dous premios de poesía e a, inclusive, dar algunha entrevista en La Voz de Galicia, con motivo da presentación dos seus libros. Non obstante as súas publicacións viñeron da man sempre de editoriais minoritarias. Se un poeta que vivise dentro das fronteiras xeográficas de Galicia tivese estes antecedentes, estamos seguros de que xa tería publicado en editoriais canónicas como Xerais ou Espiral Maior. Xavier Frías fala deste fenómeno:

Con todo, no es posible afirmar que el Grupo Bilbao tuviera o tenga un peso significativo en el planeta literario gallego actual. Aun siendo conocido, solo algunos de sus miembros están consagrados, pero la distancia física y la existencia de prejuicios sobre todo de tipo político, hacen que la existencia de un núcleo literario de expresión gallega en Madrid no tenga el eco que merece en Galicia. (Frías 2008, 74)

\section{UNHA EXOTOPÍA PARTICULAR}

Paradoxalmente, unha das cuestións que máis chaman a atención a respecto do GB é a súa definición do GB como colectivo de escritores de expresión galega (Frías 2007: 74), e non como colectivo de escritores galegos. Isto é principalmente debido á diversidade de procedencias dos seus membros. Dentro do «esquecemento» a que vimos facendo referencia ao longo destas páxinas, en 2011 fixéronse quince anos do nacemento oficial do grupo, evento soamente 
celebrado en Madrid cun simposio celebrado nas universidades madrilenas UNED e UCM. O desinterese que o GB causa entre os canonizadores galegos é, precisamente, outro dos trazos senlleiros das literaturas de fronteira.

A exotopía do GB é, porén, moi particular, case que se podería dicir que é exclusiva. Aínda que nun principio cumpre os requisitos de ser unha literatura nunha lingua A (o galego) nun territorio de lingua B (o español), danse unha serie de condicións que pasaremos a estudar a seguir. Tales circunstancias poden ser representadas así (Frías 2012: 274):



Se se comparar o Grupo Bilbao coas situacións que viven os escritores en lingua española residentes nos Estados Unidos (o modelo a partir do cal se pode considerar que xorde o concepto de exotopía, o modelo chicano do que falabamos antes e que tomamos como referencia, ou ben os escritores de expresión árabe residentes en cidades como París), vense deseguida importantes diferenzas, onde a principal é que os escritores do Grupo Bilbao non mudaron de país, de modo que as distancias non só físicas, senón tamén culturais e psico-sociolóxicas son moito menores que nos outros casos.

A relación dos escritores galegos (os de nacemento) do grupo con Galiza mantense intacta e as viaxes á terra de orixe teñen certa periodicidade. Non obstante, si comparten outra serie de características, como o esforzo por manter a lingua $\mathrm{A}$ no territorio de $\mathrm{B}$, quedando, pois, nunha situación que a miúdo cae no marxinal (de certo o galego é marxinalizado mesmo no seu propio territorio natural, de modo que en Madrid o é aínda máis). E esa é precisamente a clave para entender a existencia do Grupo Bilbao e o seu exotopía: a lingua galega. Mais cómpre engadir que a lingua é o elemento de cohesión e de atracción máis potente para persoas que non todas teñen sequera ascendencia galega.

Ao mesmo tempo, a maioría dos escritores do Grupo Bilbao (por non dicir todos) son escritores bilingües, fenómeno que tamén abunda entre os escritores de fronteira doutras latitudes. Agora ben, a heteroxénea procedencia dos autores de expresión galega do Grupo Bilbao permite entender tamén a idiosincrasia do grupo, o cal non deixa de ser o ata agora último elo na cadea de escritores e grupos de expresión galega que houbo en Madrid continuamente dende o Rexurdimento galego no século XIX, outro detalle fundamental a miúdo igno- 
rado nas historias da literatura galega. Así é estudado por Fernando Cabo a respecto da produción temperá de Rosalía de Castro (2011: 20):

Con respecto al concepto «produccción de localidad», habría que señalar que fue probablemente Arjun Appaduni el primero en utilizarlo par señalar el fenómeno aparentemente paradójico de la producción de lo local en un contexto global a partir de la generalización de los desplazamientos y migraciones, precisamente como resultado de la necesidad de constituir un entorno propio en un medio ajeno y extraño (...) Sin embargo, habría que admitir que los procesos de 'producción de localidad' no son en absoluto exclusivos del presente que tendemos a identificar con la idea de globalización. Puede incluso suponerse con una cierta plausibilidad que constituyen uno de los ejes de la noción moderna de literatura y que, como tal, se inscribe en las matrices discursivas básicas de la escritura moderna.

Tal bilingüismo do GB non deixa de ser un elemento ben significativo que ten pasado desapercibido. Se ben a lingua galega é, como vimos de afirmar, unha dos trazos de identidade do GB, o seu uso literario do español, precisamente por se tratar dun grupo transplantado a outro espazo lingüístico é algo que debe ser asumido con absoluta normalidade. En maior ou menor medida, os autores do grupo publicaron obras en castelán polo sinxelo motivo de moraren en Madrid. O facto de eles seren escritores bilingües crea arredor deles un contorno de encontro literario moi interesante. Un dos resultados desta política de encontros de linguas, precisamente nun momento histórico en que hai conflitos por como se xeste a política lingüística ao nivel estatal e autonómico, ten como resultados que dentro da colección $O$ Roibén na súa segunda época aparezan unha longa serie de traballos de autores en español cuxa obra é publicada en formato bilingüe. Entre eles, cómpre citar 18 poemas de Ángel Guinda, $20+1$ poemas de Miguel Ángel Yusta, ou Desvanes mínimos / Sobrados mínimos de Isabel Miguel, por citarmos apenas algúns títulos, todos de 2013.

Non cabe dúbida de que $O$ Roibén, a colección vinculada ao GB, é unha colección de fronteira. Naceu e mantense como órgano de expresión dos poetas de expresión galega en Madrid e, asemade, serve como ponte entre culturas, de aí a proliferación de edicións bilingües. Ao mesmo tempo, ten plena lóxica que o GB teña unha colección de seu, á vista das dificultades que supón aos seus autores publicaren en Galiza. Estamos, xa que logo, perante outra característica dun grupo literario de fronteira. Máis abaixo voltaremos a esta cuestión.

\section{ALGUNHAS CONSIDERACIÓNS FINAIS SOBRE O GB}

Como consecuencia de o GB ser un grupo literario de fronteira, existen unha serie de estereótipos que non responden á realidade. Para comezar, falar de GB e de filiación política (Acuña 2014: 287, 314) é algo que non fai sentido; aos escritores en Madrid interésalles nomeadamente a literatura e, certamente, non fan literatura para faceren política. Se ben é verdade que os grupos galegos do Madrid franquista integrados por escritores e intelectuais tiñan unha visión 
da realidade claramente política, na cal participaba a literatura, non se pode afirmar que tal cousa aconteza co GB. Embora se recoñeza que algúns dos membros máis idosos do grupo participaron nos grupos anteriores, tal visión política da literatura non se deu nin se dá no GB. Ligar o GB a formacións políticas nacionalistas non ten base, embora nalgúns momentos iniciais houbese membros afiliados a formacións nacionalistas galegas.

Dito o anterior, convén entender que o GB non ten como un dos elementos vertebradores unha identidade galega (Acuña 2014: 293). Non é así por unha razón sinxela: non todos os membros do GB son galegos e, por tanto, a identidade galega non é un elemento do que participen todos eles. Outra cousa é a lingua galega como elemento vertebrador, que si é algo crucial á hora de entender o nacemento e a posterior traxectoria do Grupo Bilbao.

Ademais, non é unha xeración, mesmo tendo en conta a discusión que hai sobre o concepto de xeración literaria. No GB conviven, polo menos, tres xeracións se atendemos aos tramos de idade, de tal xeito que o GB ten un papel de grupo de referencia literario para moitos escritores que comezaron e inclusive aínda fan a súa carreira literaria en Madrid en galego. Probabelmente moitos dos autores hoxe activos en galego non terían comezado unha carreira literaria, polo menos en galego, aínda que, se cadra, si en español.

Unha cuestión espiñenta é que o GB non é un grupo exclusivamente ligado á lingua galega. De facto, a maioría dos seus membros publicaron e publican en español (véxase máis adiante), visto que viven en Madrid. Xunto a isto, non se pode entender o GB como un grupo de exiliados. Deuse mesmo a circunstancia de que o contacto co GB fixo que autores que escribían todo en español comezasen tamén a escribir en galego, como é o caso de Luz Pichel. Esta cuestión do troque de linguas, xa mencionada anteriormente, é outro dos trazos senlleiros dos grupos de fronteira.

Canto ás coleccións literarias, o GB non estivo ligado a diversas coleccións literarias ou revistas, só a unha colección, O Roibén (Acuña 2014: 324). Todos os membros do grupo teñen publicado en distintos momentos en libros d' $O$ Roibén, actualmente editados por Lastura. Non imos afirmar que o $O$ Roibén é a colección do GB, mais si que está intimamente ligada a el. Tendo en conta que publicaron autores do grupo, galegos de fóra do grupo e tamén non galegos, non se pode afirmar que sexa o seu voceiro, mais si que se deu preferencia aos autores do GB, mesmo continúan a publicar na colección autores que non viven en Madrid, con posibilidades de editaren en Galiza (como é o caso de Verónica Martínez) ou sen tal posibilidade (como Victoria Veiguela). Non é certo que a revista Madrygal sexa unha revista do GB, embora moitos autores do GB teñan publicado nela ao longo dos anos, porque é unha revista da Universidade Complutense. As referencias que Ana Acuña (2014: 299) fai á colección Hipocampo Amigo, creada por Sabino Campos, ao que erroneamente cita como membro do GB (unha cuestión xa mencionada anteriormente) dá a sensación de que a colección tamén puidese estar vinculada ao grupo, o cal non é certo tampouco.

Unha das apreciacións máis importantes que convén facer é que a tertulia do Café Comercial na que naceu o GB e o propio GB son dúas realidades moi 
relacionadas, mais diferentes, ao contrario do que sostén A. Acuña (2014: 291, 294, 392). Nin todos os membros do GB participan dos faladoiros, nin todos os fregueses do faladoiro son membros do GB. O GB é un grupo literario, a tertulia é un punto de encontro de persoas principalmente de procedencia galega que queren falar en galego en Madrid nun ambiente nomeadamente literario no café Comercial, onde nin sequera a metade deles son escritores. Fai falla unha análise pormenorizadas das relacións existentes entre a tertulia e o grupo. Existe unha clara interconexión, até o punto de que certamente interaxen, mais non se poden confundir ambas entidades.

Finalmente, non todos os escritores galegos residentes en Madrid fan parte do GB. Non son/foron membros do GB importantes escritores e intelectuais da categoría de Borobó, Sabino Torres, Marina Mayoral, Maite Dono ou Antonio Domínguez Rey. Os dous primeiros foron -e Sabino Torres aínda o é- membros da tertulia do café Comercial, mais non do GB. Todo o cal lévanos a referirnos á denominación madrigalego aplicado ás persoas que escriben en galego desde Madrid, cuñado por Raimundo García Domínguez, Borobó ${ }^{1}$, e que non parece axeitado no uso actual que del se vén facendo profusamente Ana Acuña (2014). Entendemos que o ilustre escritor galego se referiu a aqueles intelectuais que, con efecto, non tiveron máis remedio que marchar a Madrid durante o franquismo e mantiveron vivo o galeguismo na clandestinidade durante aqueles difíciles anos. Ora ben, aplicar a denominación de madrigalegos aos membros do GB parece carente de sentido, á vista de algo que xa ficou dito antes: non todos os membros do GB son galegos e, por tanto, carecen de identidade galega, menos aínda para usar o termo como unha especie de xentilicio aplicado aos membros do grupo (aínda que na realidade o emprega para se referir a todos os intelectuais galegos residentes en Madrid). Precisamente identificar a escrita en galego con identidade galega é erróneo. Existe máis ben unha visión pessoana da lingua galega. Tamén se ten a miúdo esquecido que moitos dos escritores do GB son neofalantes (outro elemento que aínda non foi debidamente tratado) e outros son alógrafos, fenómeno ao que Alonso Montero se refería como alóglotas. Por que se dá neses autores un achegamento á lingua? Probabelmente na maioría dos casos por amor á propia lingua, certamente é así en todos aqueles que non teñan raíces galegas, e mesmo nos que as teñen, tamén a lingua vira un valor en si propio. Xavier Frías ${ }^{2}$ refírese ás experiencias persoais co galego no seu blogue do seguinte modo, recollendo esa visión pessoana a que faciamos referencia máis arriba:

Teño expresado moitas veces que me identifico plenamente coa frase de Fernando Pessoa «A minha pátria é a língua portuguesa». Tendo en conta que o

\footnotetext{
1 A respecto do concepto madrigalego, pode lerse en http://periodistascompostela.org/index.php/a-asociacion/certame-raimundo-garcia-dominguez-borobo/ (consultado abril 2014): «Un concepto, o de madrigalego, cuxa paternidade lle corresponde a Borobó, e foi galardoado co Madrigalego de Ouro na primeira edición destes premios pola Enxebre Orde da Vieira. Non en balde asinaba os seus escritos nesa terra imaxinaria chamada Madrigalicia».

2 «Die galacische Sprache und ich», in O xapo - monólogos partillados (marzo 2014): http:// frantzferentz.wordpress.com/2014/03/03/die-galicische-sprache-und-ich/ (consultado abril 2014)
} 
galego e o portugués non son realidades alleas, que o galego-portugués é parte da miña esencia, podo afirmar, mudando minimamente dúas cousas a respecto do grande Pessoa que «a miña matria é a lingua galega».

Non sou galego. Non nacín galego. Non vivín en Galiza. Porén, amo a lingua galega. Ámoa porque me apaixonei por ela. E como todos os sentimentos, un non controla por que se apaixona ou se desapaixona. Apaixoneime por esta lingua na aldea da miña nai no occidente asturiano e lanceime a falala cando tiña 17 anos, na variante local eonaviega. Desde aquela, malia todo, téñoa falado sen interrupcións. E malia todo, nunca me sentín galego. Non precisei sentirme galego para adorar esta lingua, que se converteu desde axiña na miña lingua de creación literaria (e aínda hoxe escribo os máis dos meus textos en galego).

\section{CONCLUSIÓNS}

Non está todo dito sobre o GB. Queda moito por pescudar, certamente, mais convén ter presente que o GB non é unha historia fechada, porque, embora tivese momentos de descenso, tamén soubo remontar. Desde 2010 parece que está nun momento doce de ascenso. Como grupo dinámico que é, pasan por el autores que deixan a súa pegada e, en moitos casos, despois marchan, mentres que outros chegan. No entando, nada do feito nin se diluíu nin se desdebuxou.

Xa ficou dito que o Grupo Bilbao é un grupo literario de fronteira, un grupo de exotopía, coas súas particularidades por se tratar de escritores de expresión galega en Madrid, o cal os torna substancialmente diferentes dos escritores de expresión española nos Estados Unidos. Tamén é certo que non todos os escritores de expresión galega que viven en Madrid están vinculados ao Grupo Bilbao, como xa foi dito, porque, de feito, non se teñen establecidos uns criterios ou normas para afirmar que escritores forman parte ou non do Grupo Bilbao, porque non é algo institucionalizado.

Alén diso, non se pode negar a estreita relación entre o faladoiro mensual do Café Comercial que deu lugar ao nacemento do grupo (a finais de 1996) e o propio grupo, mais si é certo que, a pesar de ser dous elementos moi relacionados, son distintos, separables, pois non todos os tertulianos forman parte do grupo, nin todos os escritores do grupo frecuentan os faladoiros, como xa nos encargamos de salientar.

Convén, xa que logo, distinguir entre escritores galegos (ou máis ben en galego) en Madrid, o Grupo Bilbao e a tertulia do café Comercial. Hai unha relación entre todos eles, mais non se pode mesturar todo e, máis aínda, aplicar a estas realidades o desafortunado cualificativo de madrigalego.

Como grupo exotópico, o GB ten a súa razón de ser no encontro de escritores de expresión galega, moitos dos cales comezan a súa carreira en Madrid, sendo os seus dous piares básicos a lingua galega e a literatura. Inferir a partir desta realidade unha consciencia política nacionalista galega é radicalmente falso. Ademais, como trazos propios do GB na confrontación con outros grupos de fronteira están o servir de ponte entre literaturas, a aparición de escritores 
alógrafos e o facto de praticamente todos eles seren escritores bilingües. Ademais, e isto tampouco está suficientemente recollido, non só o galego cohabita co español, senón tamén a miúdo co portugués, outra lingua que algúns dos escritores do grupo utilizan.

Non obstante, os novos estudos que han vir acerca do grupo e dos seus membros serán benvidos, pois son necesarios e permitirán avanzar no coñecemento dunha parte importante da literatura galega, aquela que é escrita e concibida fóra das súas fronteiras administrativas, mais non por iso inferior á que se fai na propia Galiza.

\section{BIBLIOGRAFIA}

Acuña, A. (2014) Conciencia política e literatura galega en Madrid (1950-2000), Vigo: Xerais.

Bachelard, G. (1975) (2. ${ }^{\mathrm{a}}$ ed.): La poética del espacio, México: Fondo de Cultura Económica.

Bajtin, M. (1988): Problemas de la poética de Dostoievski, México, FCE, 1986.

Bajtin, M. (1986) Problemas literarios y estéticos, México: FCE

Bajtin, M. (1988) Teoría y estética de la novela, Madrid: Taurus.

Bajtin, M. (1989) El problema de los géneros discursivos, México: Siglo XXI.

Bajtin, M. (1992) Marxismo e Filosofía da Linguagem, Sâo Paulo,: Hucitec.

Bajtin, M. (1995) Estética de la creación verbal, México: Siglo XXI.

Batlló, J. (1980): «Literatura y periferia», en Camp de l'arpa. Revista de Literatura, n. ${ }^{\circ} 75$, p. 5.

Cabo, M. (2011): «Exotopía y emergencia: La hija del mar de Rosalía de Castro», en Literatura, Espaço, Cartografías, Portugal, Centro de Literatura Portuguesa

Frías Conde, F. X. (2007). «Poesía gallega contemporánea en Madrid: el grupo Bilbao», Cuadernos del Ateneo, 24, pp. 71-110

Frías Conde, F. X. (2012) «Os 15 anos do Grupo Bilbao: algunas reflexións», Revista de lenguas y literaturas catalana, gallega y vasca, 17, pp. 273-282

García, X. L. (1984) Escolma da poesía galega 1976-1984, Barcelona, Sotelo Blanco Edicións

García, X. L. (1999) Alén do azul (Unha ducia de poetas galegos en Catalunya), A Coruña: Ediciós do Castro.

Louzao Outeiro, M. (2006) Letras de Cal na produción poética galega dos 90, A Coruña, Laiovento. 
Luna, L. (2010) «A colección O Roibén, vieiro de expresión poética do Grupo Bilbao», Revista de lenguas y literaturas catalana, gallega y vasca, 15, pp. 89-101.

Luna, L. (2012) «A colección O Roibén, vieiro de expresión poética do Grupo Bilbao», Revista de lenguas y literaturas catalana, gallega y vasca, 17, pp. 283-296

Mejía, C. (2012) «As poéticas do Grupo Bilbao: espazos e cidades», Revista de lenguas y literaturas catalana, gallega y vasca, 17, 297-304.

Regueiro, N. (2001) «A transversal ponte intercultural do Grupo Bilbao», $O$ Espello, suplemento literario de A Freita, n. ${ }^{\circ} 8$, pp. 26-29.

Seara, T. (2001): «O Roibén: Literatura galega en Madrid», Dorna, 27, pp. 163167.

Tarrio Varela, A. (1994): Literatura Galega: Aportacións a unha historia crítica, Vigo, Xerais.

Todorov, T. (1987) La conquista de América. La cuestión del otro, México, S. XXI Editores, p. 260.

Valcárcel, X. (1999): «Poetas galegos en Madrid», El Ideal Gallego, 7 de marzo, p. 21.

Yáñez, R. (2001) Lembranzas e olvidos dun estraño, Madrid, ACEF, Colección O Roibén.

Zavala, I. M. (1996) «Escribir desde la frontera», http://www.ensayistas.org/ critica/teoria/debates/iris-zavala.html (Consultado abril de 2011) 
